\title{
TIME HEALS ALL WOUNDS
}

\section{Seconds out.}

\section{BY GRACE TANG}

$\mathrm{H}$ annah's hair glowed amber in the porch light as I watched her through the semicircular pane of frosted glass. In the next second, the front door would click shut, cutting her off from my life. I willed myself to rise, to go after her and stop her, but movement was something that belonged to the next second, and the next second would not come.

Time had, as expected in my condition, slowed dramatically, and in this state I observed the world in excruciating detail: the scraps of 'meat' that had fallen from our TV-dinner trays were spreading pools of oil on the blue paper of the unpaid hospital bills. The unkempt pile lay strewn across the coffee table, and in the centre of the heap lay a half-carat diamond ring, the band scratched and faded from years of wear.

Two decades ago, on the last day that time still flowed at a regular pace regardless of my emotional state, the ring had been new and unblemished, sitting inside a ring box on my doctor's desk.

"I'm going to return it today," I choked, my forehead resting on my palm, trying desperately to hide my emotions, "it's not fair to Hannah."

Doctor Kwon sat opposite me in silence. I knew he wanted to tell me that he could up the dose of the medication again, and that the voices and hallucinations would stop, allowing me to lead a normal life. I knew he wanted to say that my disease would not gradually chip away at my personality till all that was left of me was a raving lunatic who only externally resembled my former self.

But all Doctor Kwon could do was put his hand on my shaking one. He hesitated.

"Dan, there is something that just may work."

I looked up, hopeful.

"Now don't get too excited. It's an experimental procedure, a brain surgery, never tried before in humans. A team in this hospital was going to start looking for volunteers."

I snatched the ring off the table and pushed it back into my jacket pocket.

"Sign me up."

At first it seemed as though my hallucinations had stopped after the surgery, but perhaps it was just that the nature of my hallucinations had changed. My first hot bath since the

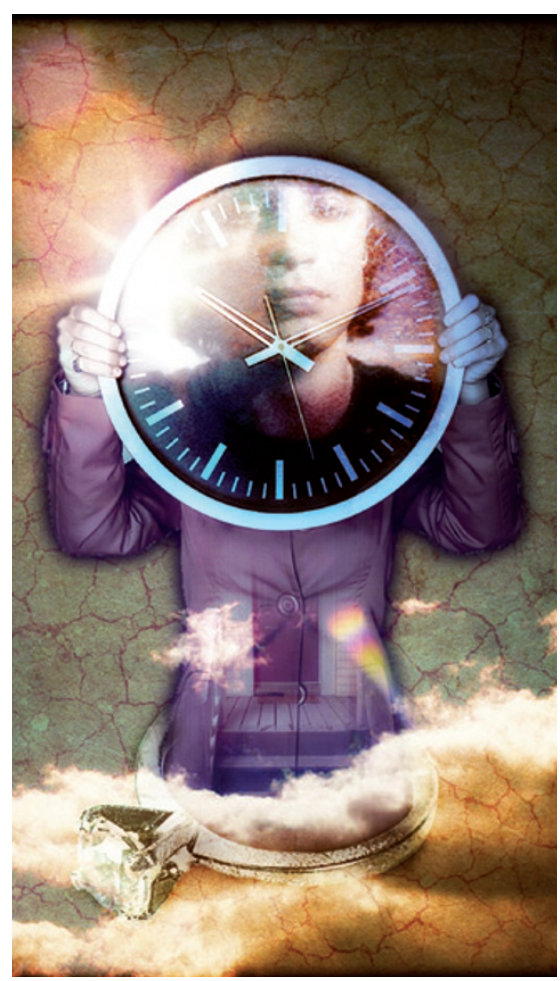

operation was glorious. I soaked in the water for what felt like hours, until I was worried Hannah would start to wonder if I had passed out. Hannah eyed me with concern when I emerged, dripping.

"Something wrong, dear? Did it hurt?" She gingerly caressed my head near the site of the surgery.

"No, that felt great."

"Then why did you come out right away?"

All too soon I was back in Doctor Kwon's office. The team that had operated on me stood by, fascinated. He held a stopwatch in one hand and offered me a piece of gum from a bowl in the other. Under his instructions, I put the gum in my mouth. I enjoyed the mint flavour immensely, but he remained silent, watching me eat until it became awkward to continue.

"Uh, should I keep going?"

He clicked the stopwatch off.

"How long have you been eating?"

"I don't know, five minutes?"

"Fascinating..."

"What?"

Out of nowhere, he hit the side of my arm. It stung.

"Ow! What was that for?"

Again, he stood there dumbly for the longest time before responding.
"Sorry. How long did the pain last when 길 I hit you?"

"Three minutes?"

"It seems that a side effect of the surgery is that emotional responses slow your perception of time. I gave you that piece of gum no more than two minutes ago ..."

It was trivial in the beginning - seconds could stretch into minutes - but my condition gradually got worse. After a year, a few seconds could drag like hours when I got emotional. It got to the point where I could no longer tell time enough to function. I lost my job, and my main source of income was the chump change time-perception researchers threw at me when they needed a guinea pig.

Tonight, Hannah had come back from her second job exhausted.

"Dan," she sighed, putting her face in her hands.

I could sense the distress in her voice, which alone was enough to trigger enough of an emotional response that time began to slow.

"Yes ... deaaar?"

Like a drunk at a party, vaguely aware of my slurred speech, I struggled to speak at a normal rate, unsure if I was succeeding.

She inhaled sharply, her voice cracking.

"I'm sorry..."

She took off her ring for the first time in 20 years. Time crawled slower than it ever had, nearly still. Was my condition deteriorating, or had I never felt such a strong emotion in my life? The diamond sparkled like a tiny glacier as it drifted through the ocean of space between her hand and the top of the coffee table.

Now the halo-like rays from Hannah's blonde crown faded like the setting sun as she descended the front stairs of the porch.

The wall clock ticked, deafening. With the arrival of the new second, the door clicked into place, but I had not moved an inch. Hannah disappeared from view. My eyelids fell, the first stage of the 300-millisecond sequence of an eye blink. The flow of air from my lungs slowed as I reached the nadir of my breath. If the Universe would progress another hundred milliseconds, my eyes would open again, and I would take my next breath. I waited and waited, but neither happened. I knew, like they said, that time would heal this wound, but time had ceased to flow.

Grace Tang is a graduate student in psychology at Stanford University. 